\title{
Revisions to Client and Professional Self-Categorisations during Reciprocal Support Groups among the Long-Term Unemployed in Finland
}

\section{Tarkiainen, Laura Elina}

Routledge - Taylor \& Francis Group 2018

Tarkiainen , L E 2018 , Revisions to Client and Professional Self-Categorisations during Reciprocal Support Groups among the Long-Term Unemployed in Finland . in M Törrönen , C Munn-Giddings \& L Tarkiainen (eds), Reciprocal Relationships and Well-being : Implications for Social Work and Social Policy . Routledge Advances in Social Work, Routledge - Taylor \& Francis Group , London , pp. 77-91 . https://doi.org/10.4324/9781315628363

http://hdl.handle.net/10138/313309

https://doi.org/10.4324/9781315628363

cc_by_nc_nd

publishedVersion

Downloaded from Helda, University of Helsinki institutional repository.

This is an electronic reprint of the original article.

This reprint may differ from the original in pagination and typographic detail.

Please cite the original version. 


\title{
5 Revisions to client and professional self-categorisations during reciprocal support groups among the long-term unemployed in Finland
}

\author{
Laura Tarkiainen
}

\section{Introduction}

In this chapter, I aim to illustrate what kinds of revised self-categorisations long-term unemployed clients and the professionals working with them recraft whilst sharing their experiences through open-ended interviews among support groups. At a wider contextual level, this chapter also presents a discussion of the importance of understanding the unique role and potential of group engagement as a reciprocally oriented social work practice. I conceptualise reciprocity as a general intention to give as well as receive in life - rather than an expectation of a tit-for-tat mutual exchange - as well as a sense of 'usefulness' to other individuals, communities or society in general (see Thompson 2013, xiii).

My analysis focusses on data collected during 15 group interviews amongst 65 long-term unemployed adults and four group interviews amongst 16 professionals who work with them. The majority of unemployed adults interviewed - whom I refer to as clients - faced multiple barriers related to their employability. These included a range of limitations, such as mental health issues, substance abuse, low education levels and complex social circumstances, all of which hampered their abilities to immediately sustain paid work. Prior to the interviews, clients voluntarily attended a support group aimed at helping them to better balance their daily lives and to generally improve their health and well-being through support from their peers and empathetic professionals in their local communities.

My analysis should be understood within a specific context. Thus, I first describe the wider social, cultural, political and institutional landscape within which my interviewees' experiences emerged and in which they are situated. I pay particular attention to the role of welfare institutions in conveying various negative and stigmatising categories as well as the reciprocal dynamics of category formation. From my research, I find that social work and welfare structures play a key role in producing and reshaping clients' self-perceptions through categorisation. Instead of being categorised by the welfare system, social work clients - particularly those with prolonged unemployment histories - may benefit from real opportunities to create new 
and empowering self-categorisations and positive views of themselves. This may be achieved through voicing and sharing their experiences in different group settings where alternative self-categorisations are reciprocally produced and constructed, both in client-to-client and client-to-professional relationships.

\section{Finnish unemployment services processing of its unemployed clients}

In unemployment research, the concept of reciprocity is often discussed in relation to the rights and duties of the citizen and the state. Different welfare regimes hold varying expectations of what it means to be a 'deserving' citizen and to what extent reciprocity is incorporated into prevailing norms about socially valued and expected behaviour. The Finnish social democratic welfare regime is based on the idea that 'everybody gives to everybody,' therefore determining if recipients of benefits and services have reciprocated remains difficult (Larsen 2006). Yet in selective welfare models, systemic reciprocity is perceived as being very low, which increases the importance of grateful and compliant attitudes among those receiving targeted benefits and services (ibid.).

Over the last decade, however, the Finnish welfare system has steadily moved towards the idea of active citizenship as its ideal, highlighting an obligation to work and an individual's responsibility, and amplifying the conditionality of welfare assistance (Keskitalo 2008). In the obligating approach, the state asks citizens to more actively fulfil their duties - such as taking part in various programmes - in return for social benefits and welfare support (see Kjørstad 2016). These policies focus on promoting selfreliance, even amongst individuals facing major social and health barriers to entering the labour market (Keskitalo 2008, Närhi and Kokkonen 2014).

Thus, similar to situations in several other welfare states, municipal social workers assume a key role in 'activating' the unemployed clients in Finland (Kroll and Blomberg 2011). Therefore, a central goal of social work lies in transforming its unemployed clients into something else (Mäkitalo and Säljö 2002a). In other words, social workers' transformative tasks aim at encouraging clients to construct identities that in one way or another relate to the labour market (Caswell et al. 2011). This means that social work's institutional practices consist of systematic attempts to produce certain kinds of people with appropriate self-perceptions by categorising them (Mäkitalo and Säljö 2002b) in order to promote and locally govern various social and labour market policies.

In Finland, social work amongst long-term unemployed clients primarily proceeds through individualised approaches. That is, social work aims to solve social problems separately for each individual, with a weak tradition of group or community-based approaches to service selection (Roivainen 2009). In particular, the culturally predominant bureaucratic adult social 
work carried out amongst long-term unemployed clients is at risk of narrowing its focus to a profession of control whereby clients are defined as dependent and passive objects of work (Juhila et al. 2003).

Paradoxically, as Vappu Karjalainen (2014) states, those most in need receive little if any institutional attention within the Finnish welfare system because institutions primarily focus on preventing individuals from becoming long-term unemployed. Some unemployed individuals are categorised as 'hopeless cases' or 'too hard to help.' That is, welfare system providers perceive them as unlikely to obtain steady employment and, therefore, provide little or inadequate support to them. In turn, those categorised as employable are targeted earlier and perceived as clients who are 'good and easy to work with.'

However, clients are not just passive participants upon whom categories are forced by institutions and social workers but active participants resisting and sometimes avoiding labour market-oriented identities and categories offered by the welfare system (Caswell et al. 2011, Tarkiainen 2017). Therefore, categorisations are not only forced upon the client but rather reciprocally negotiated and co-constructed, for example, in collaboration between the client and the social worker (Juhila and Abrams 2011, Juhila et al. 2014). Thus, in welfare practices, individuals are both constructed and engaged in constructing their own identities (see Fook 2002, p. 76, 89).

Categorisation within social work focusses on identifying clients' problems and fostering and stimulating specific capacities in a way that renders problems manageable by and within the system (Caswell et al. 2011). In this sense, social work performs as a profession that processes clients in order to place them into predetermined slots within an institution's classification system and stimulates clients to assess themselves in such terms (Hjörne et al. 2010). Thus, various competing consequential categorisations related to class, health and social problems exist within social work (Juhila and Abrams 2011).

Categorisation in social work is an extremely delicate task because assigning individuals to specific categories creates identities. Thus, how individuals are identified, categorised and labelled by others shapes their self-identifications. Therefore, social workers must be particularly conscious of their participation in categorising that produces, maintains, modifies and brokers identities; in turn, these are produced and redefined within reciprocal encounters and governed by larger welfare policies and discourses (Juhila et al. 2003, Juhila and Abrams 2011).

\section{Study aims, data and methods}

My data is drawn from the three-year Rytmi Project (2009-2011) funded by the European Social Fund. This project aimed to improve and support the health and everyday well-being of unemployed individuals. These individuals held a weak labour market position, residing in small- and medium-sized 
Finnish towns in the rural and urban areas of the Päijät-Häme and ItäUusimaa regions. To achieve these objectives, the project assisted local social and health service providers to implement a service path including physical health examinations and support groups, into existing local service structures.

Local unemployed individuals were reached via social services or local employment offices. Then, providers offered them an optional health examination and the opportunity to voluntarily take part in a professionally led, face-to-face support group that met eight times over a three- to five-month period, depending on the group. Participants had prolonged unemployment histories, and most held somewhat limited work abilities. For my study, I defined long-term unemployment as being unemployed for one year or more.

Group meetings thematically focussed on various mundane practices, such as participants' habits and routines around diet, sleep, exercise and socialising as these were embedded in their daily lives. These everyday practices were discussed and reflected upon through various group discussions and written assignments, both during and outside the group (e.g. diary methods mapped the daily routines and happenings of each participant). In addition, group participants were offered the opportunity to meet with a dietitian, while other collaborating municipalities offered group participants additional services, such as free access to local sports centres. Support groups also aimed to engage community members in various activities and interactions in order to address shared concerns.

In groups, each member was asked to set an individual midterm and easy-to-achieve lifestyle change, embedded in their everyday activities and routines, such as restructuring daily schedules, moderately reducing alcohol consumption or meeting friends on a regular basis. The core idea of the support group focussed on activating and empowering the everyday lives of individuals with the help of peers and professionals. This was achieved through gradual progress towards regaining balance in clients' everyday lives rather than immediately aiming for them to return to work. Professionals were trained to lead support groups with goal-oriented and empowering methods, which did not explicitly focus on reciprocity or mutual aid.

Most participants needed rehabilitative services prior to gaining employment, while some, in fact, perceived themselves as unemployable (see Tarkiainen 2017). Participants represented a heterogeneous group in terms of age, gender, educational attainment and employment histories, yet most shared a low level of education and sporadic work histories. Wishes to engage in meaningful activities during the day, to meet peers and to make level-headed changes in their lives were identified as reasons to participate in the group.

Two pilot studies were conducted within the larger project in order to localise solid support group practices, which were then related to the existing service structures. In the project, an action-research approach and the 'User Participation in Quality Assessment' (Krogstrup 1997) method 
was used to collect, analyse and report data. In keeping with the actionresearch method, both clients and professionals played a key role in improving the services at hand and were, therefore, interviewed. All face-to-face interviews were carried out in various institutional settings where groups normally gathered, such as in social service and rehabilitative units and local community centres. Three project members conducted the interviews, including myself.

Prior to the interviews, interviewers observed the last support group meeting after permission was granted in order to gain insight into each group. Each group had three to eight participants, and almost all participants were interviewed, excluding those who dropped out (around one-fifth of all participants). One limitation to this data set lies in the lack of interviews among dropouts; most likely, the group interview dynamics influenced the ways that interviewees shared their thoughts. Thus, the pitfalls, complexities and critical voices regarding the support group experiences remained mostly silent.

Each interview lasted approximately one to two hours. Client interview questions focussed on participants' experiences within the support group they attended as well as their previous experiences as service-users. During the interviews, we asked participants how the support group model could be improved, to identify the benefits and weaknesses of the group and how this group compared to previous service experiences that they had as unemployed service-users. In addition, we were interested in the professionals' experiences. After organising 15 group interviews among clients between 2010 and 2011, we conducted four group interviews among 16 professionals in 2011. Professionals represented health, social work and rehabilitation service providers.

The local ethics committee approved the project's study, whereby the study and data collection met all ethical principles, such as confidentiality and the possibility of withdrawing from the study. During all interviews, we used a semi-structured interview guide, whereby the open-ended questions posed depended on how each interview evolved. Each participant signed an informed consent form prior to the interview, and all interviews were audiotaped and then transcribed to text, resulting in 350 pages of client interview data and 85 pages of professional interview data. Interviews were conducted in Finnish, while excerpts were translated into English.

Furthermore, the interviews were not specifically on self-categorisations nor on reciprocity; however, I obtained permission to use the data collected during the project for my own analysis. In this, I focussed on the revised self-categorisations posed by interviewees, despite my awareness that the interview situation itself influenced self-categorisations. In my analysis, I ask,

What kinds of revised self-categorisations do long-term unemployed clients and professionals working in unemployment services create through their discourse when they share their experiences within a support group? 
Here, I focus on the revised self-categorisations that emerged in the discourse during interviews and seek to identify in what ways interviewees self-categorise. In my analysis, I first read through the data in its entirety several times and coded it inductively, thereafter rereading it. When sifting through the data, I tracked the revised self-categorisations, both in client and professional interviews, reading through the transcripts again and specifically focussing on those revisions. Subsequently, I focussed on extracts from my data dealing with self-categorisations and mapped them according to the key recurring themes that emerged during the interviews. As a result of my analysis, I grouped five self-categorisations under the themes of revised client categorisations and revised professional categorisations. In what follows, I use ten excerpts from the interviews to illustrate various points in my analysis.

\section{Revised client categorisations}

First, in my analysis, I focus on clients' revised self-categorisations, which I have identified as follows: 'active life changer', 'supporter' and 'equally encountered'.

\section{Active life changer}

In my data analysis, I noticed that clients included extensive descriptions of re-examining their prior selves and envisioning future potential alternative self-categorisations. For example, individuals expressed some hope as they potentially moved closer to becoming fit for work and living a stable and active life:

I think this group has been a great experience. These meetings and all these people I got to know have been wonderful. When I was just at home, I did nothing but sit at the computer, going to the fridge and lazing on the sofa. Now, because of this group, I gained some ideas of how to change my own life and I can now see, that, wow, things can go this other way as well. This has had a real influence on me. Outside this group some of us have started to take walks together and those walks have been huge sources of supports to me as well. We can catch up and share our experiences and thoughts, which has been really important.

(Client interview 1)

This interviewee categorised herself as being an 'active life changer' as opposed to the 'passive layabout' she had felt she was previously. In this way, the interviewee moved beyond the negative unemployment identity and formed her own more positive self-image. Her revision of her selfcategorisation is visible in the way she describes herself - feeling engaged, supported and living an active life. 
During the interviews, clients repeatedly argued against the dehumanising classification mechanisms embedded in the service system for Finland's unemployed. In particular, the support group's focus on mundane habits and improving everyday life proved appealing, ultimately prompting attendance. However, for many clients, simply having the courage to take part in and commit to the support group represented a significant achievement. In the excerpt below, one interviewee discussed why he previously avoided peer and support groups and why he now chose to take part:

I have never been a group-spirited person really - never previously considered peer groups. Let's say groups like Alcoholics Anonymous must have a good atmosphere, but it only involves sharing what happened and how much I've drunk and never focuses on describing your good sides and describing me as a human being. You don't really get to know yourself when you always tell the same story about being 14 and waking up in a ditch and the police picking me up. So, you sort of tell the same story over and over again, and it doesn't really move on from there. Then, I came to this group, because I need to improve my everyday life for myself and my health. Even small things are big things - a change and improvement for the better. Like having a hangover just once a month is already a big change for me. So, through this group, I sort of woke up that, damn it, does it have to be like this? I've been asked to take part in a community centre in my neighbourhood. They have all kinds of activities, so I could participate and change. It's only 100 metres away from my place. I could go there when they meet. There are all kinds of people, playing cards and doing all kinds of things. Anyway, by going, I could change my life a bit, because sometimes my life is bloody depressing.

(Client interview 2)

In the above extract, the interviewee defines himself by using the alcoholic category but seeks to view his problematic alcohol consumption as a part of his ordinary everyday life, which also featured some good elements and positive characteristics. The interviewee looks at his 'depressing life' from a different perspective after attending the group, which also renders him as a potential 'life changer'.

In addition, the interviewee recounts how he avoided peer support groups because he wanted to be seen beyond the category of alcoholic-in other words, as a human being. Previously, he was not motivated to attend any groups because he thought the problem category labels explicitly lay at the centre of the groups' attention. According to the client, peer and support groups based on problem categories encourage the internalisation of a deviant category, whilst other more positive self-categorisations remain easily submerged.

Many clients highlighted the importance of the group's holistic approach and focus on everyday life, which takes into account the humanness of all 
participants. Furthermore, the group's approach, to a certain extent, invalidated the categorical labels often used in various individual and groupbased social work practices, such as alcoholic, mentally ill and the long-term unemployed.

\section{Supporter}

According to clients, opportunities for reciprocity created through sharing experiences strengthened their senses of normalcy and belonging whilst diminishing their feelings of being less valuable in comparison to others. Clients described a variety of reciprocal helping processes between support group members by categorising themselves as holding dual roles, that is, as people who receive but also provide support. Below, one interviewee describes his own self-image as somehow inadequate and devalued in his own and others' eyes before he attended the support group:

For me, in this group, I realised that I am not the only one who struggles with these issues. I thought I was alone in this community. But, there are other people as well who have some difficulties. It has helped me a lot to move forward. It has made me feel better, and now I do not always blame myself and feel guilty. I am not always the only one to blame. I have realised that there are others who go through the same thing and who have their own problems. While we don't really know each other, we've been able to speak about our issues. And, funnily, it has helped me, since I've been able to help other people and been able to speak.

(Client interview 3)

As shown in the extract above, this interviewee describes how persistent feelings of alienation eroded when hearing peers' experiences that mirror his own. Consequently, his self-categorisation as an inadequate person shifted to someone who had gained a sense of normalcy. Here, we see that the interviewee is particularly pleased that he could help others and was involved in a two-way process. In other words, he was able to adopt the role of 'supporter' when aiding others.

In addition, groups offered hope and alternative explanations, which, in turn, limited the stigma attached to long-term unemployment, which is often accompanied by shame, guilt and self-recrimination. By gaining some perspective through reciprocity, interviewees could see the structural and shared underlying reasons behind individual experiences originating and existing outside themselves:

This group has been really different to what I have at home. I live in a troubled family, and this is very different. This gives you a good kick, I think. It makes me think that there are other things in life, not just 
what I have at home. Here, you encounter different people and you realise that other people aren't doing that well either. This provides some sort of new beginning to something, especially for those of us with long unemployment histories. Through this group, I can get some kind of ventilation to my brain. So, I am not only thinking about if I can afford to buy food. At least I have something to say to others.

(Client interview 10)

As seen here, being able to witness how others cope helps many clients shift their perspectives and self-reflect by recognising one another. In the extract above, the interviewee explains how she does not categorise herself and her situation as particularly 'problematic' based on the reciprocator role she adopted after sharing her experiences within the group setting.

Reciprocal acts may indeed provide a mechanism for redefining one's identity, maintaining a positive self-image and regaining control over one's life. This suggests that reciprocity plays a role in discrediting definitions of one's self (Hutchinson and Lovell 2013). Thus, the support group can affirm one's personal worth and individuality when one reflects on their own situation. In this way, one can recognise and understand shared experiences and co-construct them as well as self-categorise and reorient oneself in alternative ways. Reciprocity is particularly meaningful for those who depend upon others and are often conceptualised in a one-dimensional manner: as takers, passive recipients and 'burdens' to others (see Thompson 2013). In these terms, reciprocity is an important aspect of managing one's identity in relation to others because, without reciprocal encounters, one must manage an identity at the margins and in solitude.

\section{Equally encountered}

Clients described their previous relationships with service providers as typically unequal, asymmetrical and contractual. The vast majority of clients had previously experienced negative and humiliating encounters in welfare services; thus, the support group run by empathetic professionals became particularly helpful for many. Due to previous unpleasant experiences, clients stressed the importance of being at the 'same level' and being able to self-categorise themselves as 'equally encountered', as illustrated in the following:

We as a group have been quite talkative, and the professionals also share their thoughts and experiences. At first, I used a few swear words with my wife regarding why on earth I was put into this group. But, it was only because I didn't know what this was all about. I have enjoyed this group a lot. And, I really like the fact that professionals themselves participate in it. It is not like the normal interview situation.

(Client interview 12) 
This interviewee categorises himself as occupying the same level as the professionals. This professional involvement challenged his previous experiences in professional-client relationships, in which he often felt that encounters represented a special hierarchical relationship, and he was simply an object of work in which the categorical difference was constructed in one way or another. In these relationships, professionals assume the roles of non-participating interviewers.

In general, according to clients, support groups offered an atmosphere filled with respect and recognition of them as fellow human beings. In addition, such groups facilitated authentic and trusting relationships characterised by blurred professional roles:

We have had lots of humour and we've been able to speak about things using real terms; I think I got some hope through this group. I've really enjoyed the good sense of humour among professionals. All of us are on the same level, and most importantly they [professionals] do not look down on us - like uh 'we are professionals and we know'.

(Client interview 13)

Clients emphasised the importance of not being looked down upon by professionals in these support group settings. Therefore, in contrast to controlling and bureaucratic encounters with professionals, feeling respected and on equal footing represented a particularly important experience for clients. Rosemary Green et al. (2006) believe that the expert and 'knower' role of social work professionals can create unnecessary boundaries, an imbalanced distribution of power and an artificial distance between the client and worker. Thus, I found that the support group experience broke down barriers between professionals and clients and, to a certain extent, challenged the power dynamics between them. As such, the dichotomy between professional and non-professional can be reconstructed and re-examined in order to achieve equity and reciprocity within social work practices.

\section{Revised professional self-categorisation}

In the following section, I focus on professionals' revised self-categorisations, which I identified in my analysis as 'professionally grown' and 'bystander'.

\section{Professionally grown}

The support group was not simply a one-way process. Professionals also reported benefitting from the experience. In general, the support group offered them a chance to critically re-examine their own practices and professional standings. However, this required some reflection and work by the professionals: 
Through this group, I understand that the things that are good for me are not necessarily good for clients. So, if the client is satisfied - let's say by having booze - I can disagree with the client, but not look at him or her from a top-down perspective like unemployed clients are usually looked at. I have worked quite hard on this, or realised through this group that for many people to even come to a group like this and participate is a major effort.

(Professional interview 4)

In the extract above, the interviewee explains how the group experience allowed her to rethink her own attitudes and prejudices regarding the clients' ways of life, capabilities and service needs. This process also led to a critical reflection of the imbalance of power in the client-professional dynamic. Consequently, the interviewee sees herself as experiencing 'professional growth' as a result of support group attendance.

Many professionals pointed out how they made a special effort to help clients feel appreciated and valued by avoiding judgemental views or by not 'stepping above' them. I understand this as a process of reciprocity and shared learning. Here, I agree with Sue Thompson (2016), who suggests promoting reciprocity and appreciating that feeling valued plays a key role in social work. This results from a value base espousing self-worth and importance because the core idea of the profession is to challenge a variety of discriminatory assumptions and practices.

Understanding how support groups helped professionals gain new roles also allows us to understand professional growth. The support group not only influenced the ways that professionals were perceived within the group but also how they were perceived outside the group in their daily practices:

I think this group provided a new situation for all of us, where both professionals and clients were in a group and talked together. I had some kind of a dual role. I normally work at a bureaucratic office, which is the only place where my clients meet me. So, now, due to this group, I noticed that clients perceive me and my working role at the office differently. It's easier for them to open up and share their thoughts at the office now when we've gone through this group together. In a way, this group changed my role at work quite a bit after I gave something of myself.

(Professional interview 1)

Here, the interviewee explains how the support group helped her clients see her beyond the bureaucratic role in her daily practice. As she explained, the successful support group experience required professionals to both give and receive. Interviewees explained how they shared their own experiences from their everyday lives, such as their struggles and difficulties around dieting, exercise and everyday activities. By giving something of themselves to the 
clients, professionals also reported gaining something in return, as we see in the extract above.

Carla Alexander and Grant Charles (2009) argue that a lack of reciprocity in welfare services may dehumanise and create artificial and restrictive barriers between clients and professionals. As we see above, the dual role of professionals is described as only positive; however, it may bring some complexities and challenges, both to clients and professionals. For example, exploitation and potential harm and damage to the client or professional may occur if such practices are not conducted ethically (see, for example, Reamer 2003, Pugh 2007).

\section{Bystander}

In addition, all of the professionals interviewed described various client-toclient support processes that helped clients validate and reaffirm themselves as valued citizens and contributors to society. This required an unusual role and level of activity from the professionals:

I was really surprised how the clients started to share their thoughts openly and honestly, and how they gained trust between each other. We laughed and cried, and some clients had quite difficult stories to share. I was quiet quite a lot since the clients were supporting each other by giving each other tips and so on. It surprised me how human we were to one another. The clients first thought that the group was a sanction and coercive, but then it was something else. I was surprised - the same way they were.

(Professional interview 1)

Here, the interviewee categorises herself as a 'bystander' in the support group and its various helping processes. By not assuming a dominant role, clients had the opportunity to share their knowledge, skills, emotional support and experiences as reciprocators. Often, in welfare services, clients are described as being in need of help whilst simultaneously unable to give help and contribute to the well-being of others.

Professionals recognised the need to identify service-users' competencies to reciprocate at an organisational level. That is, support groups were viewed as a way of facilitating reciprocity and sharing:

I was sort of withdrawing when clients started to speak about their shared experiences, like sleeping problems. They were sharing things that they found helpful and by sharing they were giving support to each other. It was somehow shocking to me that the clients did not previously have a place to share their experiences and deal with their life in its entirety. So, it feels to me that there is a real need for sharing experiences in this society. 
Here, the interviewee describes her 'bystander' role as important to the support group's success. Professionals felt a real need for sharing and voicing their experiences among long-term unemployed individuals. Allowing for such experiences within welfare services is key because one's dignity may be affronted if insufficient opportunities exist for people to do things with and for other people (Thompson 2013, p. 7).

\section{Conclusions}

My analysis reflects the idea that in support groups, clients are identified beyond the compelling categories professionals and welfare institution providers use. Support groups offer not only a chance to be seen beyond specific categories but also the opportunity to assume new identities. This, in turn, simultaneously diminishes the self-blame and guilt felt by clients and enables professional growth amongst providers.

These results demonstrate that being recognised and treated as a valued human being beyond such categories represents vital experiences for those with prolonged unemployment histories. Therefore, individuals working within the social work profession should not view their clients as simply representing a harmful diagnosis or as problem cases. In particular, longterm unemployed social work clients may benefit from services that create a sense of normalcy and connectedness. This may also help clients to adopt a critical stance towards loaded and contested institutional and cultural categories rather than being confined by them.

We all rely on judgements from others, which provide additional opportunities for us to adapt and maintain positive self-images. These also allow for the formation of a positive identity, thus reshaping the stigmatised role of 'passive recipient' often assigned to unemployed individuals. From a social work perspective, how social work clients are viewed, how they see themselves and what kinds of labels are assigned to them remain crucial. Rather than relying on professional expertise related to the problem of unemployment, a greater range of critical voices should be heard regarding unemployment and its causes. These voices could be co-created through client-professional relationships as well as between peers. Relinquishing hierarchical relationships encourages positive client self-categorisations to emerge. It also confronts oppressive power dynamics, restrictive barriers and any separation between professionals and their clients, helping professionals to view themselves in new roles.

In addition, social work requires an understanding of the two-sided relationship and participation in reciprocal identity-making created through categorisation. Clients are not simply passive recipients of help and support; rather, they should be supported as active partners in various support processes. Therefore, social work as a field may move from imposing categories on clients to mutually enabling self-categorisation utilising various relationship-based practices to invoke alternative and positive categorisations 
constructed reciprocally (Juhila and Abrams 2011). In particular, social work that pursues change is based on a client's recourse, strengths and capacities, which, in turn, create positive identities (Juhila et al. 2014, p. 23). In social work among unemployed clients with complex histories and needs, greater effort could be directed towards addressing gradual and reciprocal processes and linking (as opposed to distancing) services not necessarily aimed at employment alone.

\section{References}

Alexander, C., and Charles, G., 2009. Caring, Mutuality and Reciprocity in Social Worker-Client Relationships. Rethinking Principles of Practice. Journal of Social Work, 9 (1), 5-22.

Caswell, D., Eskelinen, L., and Olesen, P., 2011. Identity Work and Client Resistance Underneath the Canopy of Active Employment Policy. Qualitative Social Work, 1 (1), 1-16.

Fook, J., 2002. Social Work. Critical Theory and Practice. London: SAGE Publications. Green, R., Gregory, R., and Mason, R., 2006. Professional Distance and Social Work: Stretching the Elastic? Australian Social Work, 59 (4), 449-461.

Hjörne, E., Juhila, K., and van Nijnatten, C., 2010. Negotiating Dilemmas in the Practices of Street-level Welfare Work. International Journal of Social Welfare, 19 (3), 303-309.

Hutchinson, A., and Lovell, A., 2013. Participatory Action Research: Moving Beyond the Mental Health 'Service User' Identity. Journal of Psychiatric Mental Health Nursing, 20 (7), 641-649.

Juhila, K., and Abrams, L., 2011. Special Issue Editorial: Constructing Identities in Social Work Settings. Qualitative Social Work, 10 (3), 277-292.

Juhila, K., Günther, K., and Raitakari, S., 2014. Negotiating Mental Health Rehabilitation Plans: Joint Future Talk and Clashing Time Talk in Professional Client Interaction. Time \& Society, 24 (1), 5-26.

Juhila, K., Pösö, T., Hall, C., and Parton, N., 2003. Introduction: Beyond a Universal Client. In Christopher Hall, Kirsi Juhila, Nigel Parton, and Tarja Pösö (eds.) Constructing Clienthood in Social Work and Human Services. Interaction, Identities and Practices. London: Jessica Kingsley Publishers, 11-26.

Karjalainen, V., 2014. Poliittisen harkinnan paradoksit. Kohderyhmänä pitkäaikaistyöttömät. In Laura Kalliomaa-Puha, Toomas Kotkas, and Marketta Rajavaara (eds.) Harkittua? Avauksia sosiaaliturvan harkintavallan tutkimukseen. Helsinki: Kelan tutkimusosasto, 114-133.

Keskitalo, E., 2008. Balancing Social Citizenship and New Paternalism: Finnish Activation Policy and Street-level Practice in a Comparative Perspective. Helsinki: Stakes.

Kjørstad, M., 2016. Do Your Duty - Demand Your Right: A Theoretical Discussion of the Norm of Reciprocity in Social Work. European Journal of Social Work, doi:10.1080/13691457.2016.1246416.

Krogstrup, H., 1997. User Participation in Quality Assessment. A Dialogue and Learning Oriented Evaluation Method. Evaluation, 3 (2), 205-224.

Kroll, C., and Blomberg, H., 2011. Social Work-fare? Social workers' Views on the Poor, the Unemployed and Workfare-related Measures in Finland. In 
H. Blomberg, and N. Kildal(eds.) Workfare and Welfare State Legitimacy. Helsinki: University of Helsinki, Nordic Centre of Excellence NordWel, 96-124.

Larsen, C., 2006. The Institutional Logic of Welfare Attitudes. How Welfare Regimes Influence Public Support. Ashgate: Hampshire.

Mäkitalo, Å., and Säljö, R., 2002a. Talk in Institutional Context and Institutional Context in Talk: Categories as Situated Practices. Interdisciplinary Journal for the Study of Discourse, 22 (1), 57-82.

Mäkitalo, Å., and Säljö, R., 2002b. Invisible People: Institutional Reasoning and Reflexivity in the Production of Services and "Social Facts" in Public Employment Agencies. Mind, Culture, and Activity, 9 (3), 160-178.

Närhi, K., and Kokkonen, T., 2014. Transformation of Participation Politics and Social Citizenship in Finnish Welfare Governance. In Aila-Leena Matthies, and Lars Uggerhoej (eds.) Participation, Marginalisation and Welfare Services Concepts, Politics and Practices Across European Countries. Ashgate: Surrey, 95-112.

Pugh, R., 2007. Dual Relationships: Personal and Professional Boundaries in Rural Social Work. British Journal of Social Work, 37 (8), 1405-1423.

Reamer, F., 2003. Boundary Issues in Social Work: Managing Dual Relationships. Social Work, 48 (1), 121-133.

Roivainen, I., 2009. Does Community Work in Finland Benefit Citizens or Clients? In Gunn Strand Hutchinson (eds.) Community Work in the Nordic Countries. New Trends. Oslo: Universitetsforlaget, 98-118.

Tarkiainen, L., 2017. Long-term Unemployed Finnish Interviewees Address Deservingness: Separating, Declining and Enriching as Means of Resisting. Journal of Poverty and Social Justice, 25 (3), 219-231.

Thompson, S., 2013. Reciprocity and Dependency in Old Age. Indian and UK Perspectives. New York: Springer.

Thompson, S., 2016. Promoting Reciprocity in Old Age: A Social Work Challenge. Social Work in Action, 28 (5), 341-355. 